\title{
ANALISIS VOLUME LALU LINTAS PADA RUAS JALAN ARTERI (BATAS. KABUPATEN. MAJENE-POLEWALI MANDAR)
}

\author{
Fitriani Basri, Milawaty Waris, Muhammad Harum \\ Prodi Teknik Sipil, Fakultas Teknik, Universitas Sulawesi Barat, \\ JL.Prof.DR.Baharuddin Lopa. Lutang. Majene.Tlp/Fax(0422)22559 Kode Pos 91413 \\ Email: fitriani08121996@gmail.com
}

\begin{abstract}
ABSTRAK
Penelitian ini dilakukan di Jalan Prof. Dr. Baharuddin Lopa Lutang Majene tepatnya batas Majene - Polewali Mandar.Kebutuhan yang dibutuhkan dalam penelitian ini, khususnya di lokasi penelitian adalah data volume lalu lintas yaitu sepeda motor (MC), kendaraan ringan (LV), kendaraan berat (MHV), Kendaraan truk besar (LT), kendaraan bus besar (LB).Tujuan penelitian dilakukan untuk menganalisis volume Lalu Lintas Harian (LHR) pada ruas jalan arteri trans Sulawesi (Batas Majene- Polewali Mandar). Mengetahui perbandingan volume Lalu Lintas Harian (LHR) dalam dua (2) tahun terakhir. Pengaruh tingkat volume jalan terhadap arus lalu lintas yang paling tinggi pada hari senin pukul 08.00 dan 17.00 WITA yang paling rendah pada hari Minggu pukul 13.00-14.00 wita dengan nilai 0,13 smp/jam, dengan mengacu pada Manual Kapasitasjalan Indonesia.
\end{abstract}

Kata Kunci: Volume Lalu Lintas Harian (LHR) dan Perbandingan Volume Lalu Lintas.

\begin{abstract}
This research was conducted at Prof. Dr. Baharuddin Lopa Lutang precisely Majene Majene limit - Polewali.Needs required in this study, especially in the research area is the volume of data traffic that is motorcycle (MC), light vehicle (LV), heavy vehicles (MHV), Vehicle big truck (LT), major bus vehicle (LB).The aim of research was conducted to analyze the volume Daily Traffic (LHR) on arterial roads Trans Sulawesi (Limit Majene- Polewali). Knowing the volume ratio Daily Traffic (LHR) within two (2) years. The influence of the volume level of the current highest traffic on Monday at 08:00 and 17:00 pm lowest on Sunday at 13:00 to 14:00 pm with a value of 0.13 smp / hour, With reference to the Manual Kapasitasjalan Indonesia.
\end{abstract}

Keywords: Daily traffic volume and Comparative Traffic Volume. 


\section{PENDAHULUAN}

Arus lalu lintas merupakan parameter kemajuan dari suatu daerah pada sisi perkembangan kendaraan yang melintas di jalan raya. Arus lalu lintas lancar dan teratur dapat menunjukkan bahwa kendaraan bergerak sesuai dengan rambu lalu lintas yang ada di jalan raya.

Volume lalu lintas adalah jumlah kendaraan yang melewati suatu penampang tertentu pada suatu ruas jalan tertentu dalam satuan waktu tertentu. Volume lalu lintas rata-rata dihitung menurut satu satuan waktu tertentu, bisa harian yang dikatakan sebagai volume lalu lintas harian rata-rata(LHR). Volume lalu lintas menunjukkan jumlah kendaraan yang melintasi satu titik pengamatan dalam satu satuan waktu (hari, jam, menit). Sehubungan dengan penentuan jumlah dan lebar jalur, satuan volume lalu lintas yang umum dipergunakan adalah lalu lintas harian rata-rata, volume jam perencanaan dan kapasitas, Sukirman (1994).Mobilitas penduduk memerlukan sarana dan prasarana transportasi yang memadai, aman, nyaman dan terjangkau. Seiring meningkatnya perekonomian dibarengi dengan membaiknya pendapatan penduduk sehingga, daya beli masyarakat kebutuhan sarana transportasi berupa sepeda motor maupun mobil untuk digunakan sebagai sarana angkutan untuk bepergian. Akibatnya, pertumbuhan kendaran lalu lintas pada ruas jalan arteri trans Sulawesi semakin bertambah. Hal menimbulkan permasalahan berupa meningkatnya volume lalu lintas yang berdampak pada tingginya kepadatan lalu lintas pada ruas jalan arteri yang menghubungkan dua kabupaten, yaitu Kabupaten Majene da Polewali Mandar, terutama pada tititk ruas Lutang.

Perkembangan pembangunan khusus perbaikan Jalan Trans Sulawesi yang baik telah berdampak pada meningkatnya pergerakan volume lalu lintas dari tahun ketahun mengalami peningkatan sebagai dampak tarikan, sebagai pusat pendidik tinggi di Sulawesi Barat, perkembangan Kampus Universitas Sulawesi Barat, pelayanan administrasi umum, dan adanya hubungan sosial ekonomi antara kedua Kabupaten Polewali Mandar dan Majene.

Interaksi sosial dan mobilitas penduduk yang tinggi berdampak pada peningkatan volume lalu lintas di ruas jalan yang menyangkut area kabupaten. Aktifitas penduduk yang mengalami peningkatan mengakibatkan volume lalu lintas pada ruas Jalan Trans Sulawesi meningkat secara drastis. Faktor-faktor ini di duga sebagai pendorong pelajar dari berbagai kabupaten yang menuntut ilmu di kabupaten Majene. Untuk itu penulis mengambil sebuah judul “ Analisis Volume Lalu Lintas Pada Ruas Jalan Arteri (Batas. Kabupaten Majene - kabupaten Polewali Mandar).

\section{METODE PENELITIAN}

\section{A. Lokasi dan Waktu Penelitian}

1. Lokasi Penelitian

Lokasi penelitian dilakukan di ruas jalan arteri Trans Sulawesi yang secara administrasi pemerintah berada di jalan Prof. DR. Baharuddin Lopa Kelurahan Tande Timur Lingkungan Lutang. 
Lokasi penelitian dapat dilihat pada gambar dibawah ini :

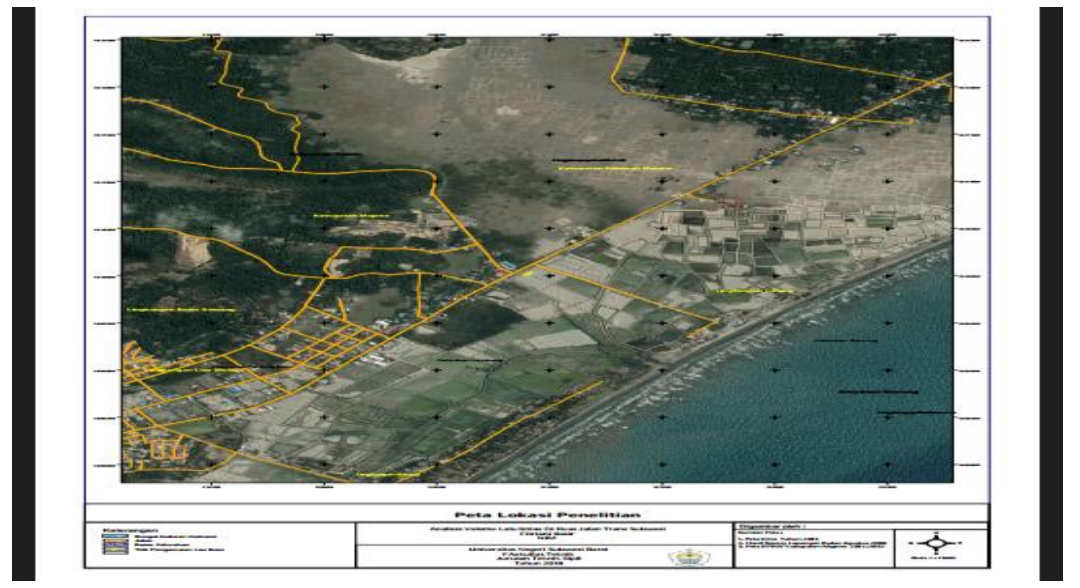

Gambar. 1 Lokasi Penelitian

2. Waktu Penelitian

Penelitian dilaksanakan selama dua (2) bulan dimulai dari Bulan Agustus sampai September 2018.

\section{B. Objek Penelitian}

Objek penelitian ini yang dilakukan adalah volume lalu lintas pada ruas jalan arteri (batas. Kabupaten Majene - Polewali Mandar)

\section{Teknik Pengumpulan Data}

1. Teknik Pengamatan

Teknik pengamatan yang digunakan adalah metode survei dengan cara menghitung lansung kendaraan dilokasi penelitian.

2. Teknik Dokumentasi

Mengambil gambar secara lansung dilokasi penelitian.

3. Pengolahan Data

Data yang terkumpul dari lokasi penelitian diolah menjadi jawaban untuk menghitung volume lalu lintas harian ruas jalan arteri (batas. Kabupaten Majene - Polewali Mandar).

3. Alat Penelitian
1. Lembar Observasi
2. Catatan Harian
3. Stop watch
4. Meter pita standar
5. Kamera

4. Tindakan Penelitian

1. Pengumpulan data penelitian

Pengumpulan data dalam penelitian bersumber dari berbagai jurnal dan buku yang berhubungan dengan Volume Kendaraan. Sehingga pengguna cara ini peneliti dapat mengetahui masalah tentang volume kendaraan ruas jalan arteri (batas. Kabupaten Majene - Polewali Mandar). 
2. Pengamatan dilapangan

Pengamatan dilakukan lansung dilokasi penelitian untuk mengetahui dan mengerti bagaimana kondisi yang terjadi dilokasi penelitian.

\section{Teknik Analisis Data}

\section{Data Volume Lalu Lintas}

Kebutuhan yang dibutuhkan dalam penelitian ini, khususnya di lokasi penelitian adalah data volume lalu lintas yaitu sepeda motor (MC), kendaraan ringan (LV), kendaraan berat (MHV), Kendaraan truk besar (LT), kendaraan bus besar (LB). Pengumpulan data dilakukan dengan cara menghitung langsung jumlah kendaraan yang melewati titik pengamatan dengan menggunakan pencatatan secara manual setiap 15 menit selama jam sibuk. Survei dilakukan oleh dua surveyor pada titik pengamatan untuk setiap arah lalu lintas. Kemudian pencatatan kecepatan kendaraan, dilakukan untuk mengukur kecepatan dibatasi pada jarak per 50 meter, yang diwakili 5 kendaraan untuk masing-masing tipe kendaraan.

2. Kapasitas

$$
C=C_{o}+F C_{W}+F C_{S P}+F C_{S F}+F C_{C S}
$$

\section{Keterangan:}

$$
\begin{array}{ll}
C & =\text { Kapasitas }(\mathrm{smp} / \mathrm{jam}) \\
C o & =\text { Kapasitas dasar (smp/jam) } \\
F_{C W}= & \text { Faktor penyesuaian lebar jalan } \\
F_{C S P}= & \text { Faktor penyesuaian pemisah arah (hanya untuk jalan } \\
& \text { tak terbagi) } \\
F_{C S F}= & \text { Faktor penyesuaian hambatan samping dan bahu jalan } \\
F_{C C S}= & \text { Faktor penyesuaian ukuran kota. }
\end{array}
$$


6. Bagan Alur Penelitian

Adapun langkah-langkah pengolahan berikut ini:

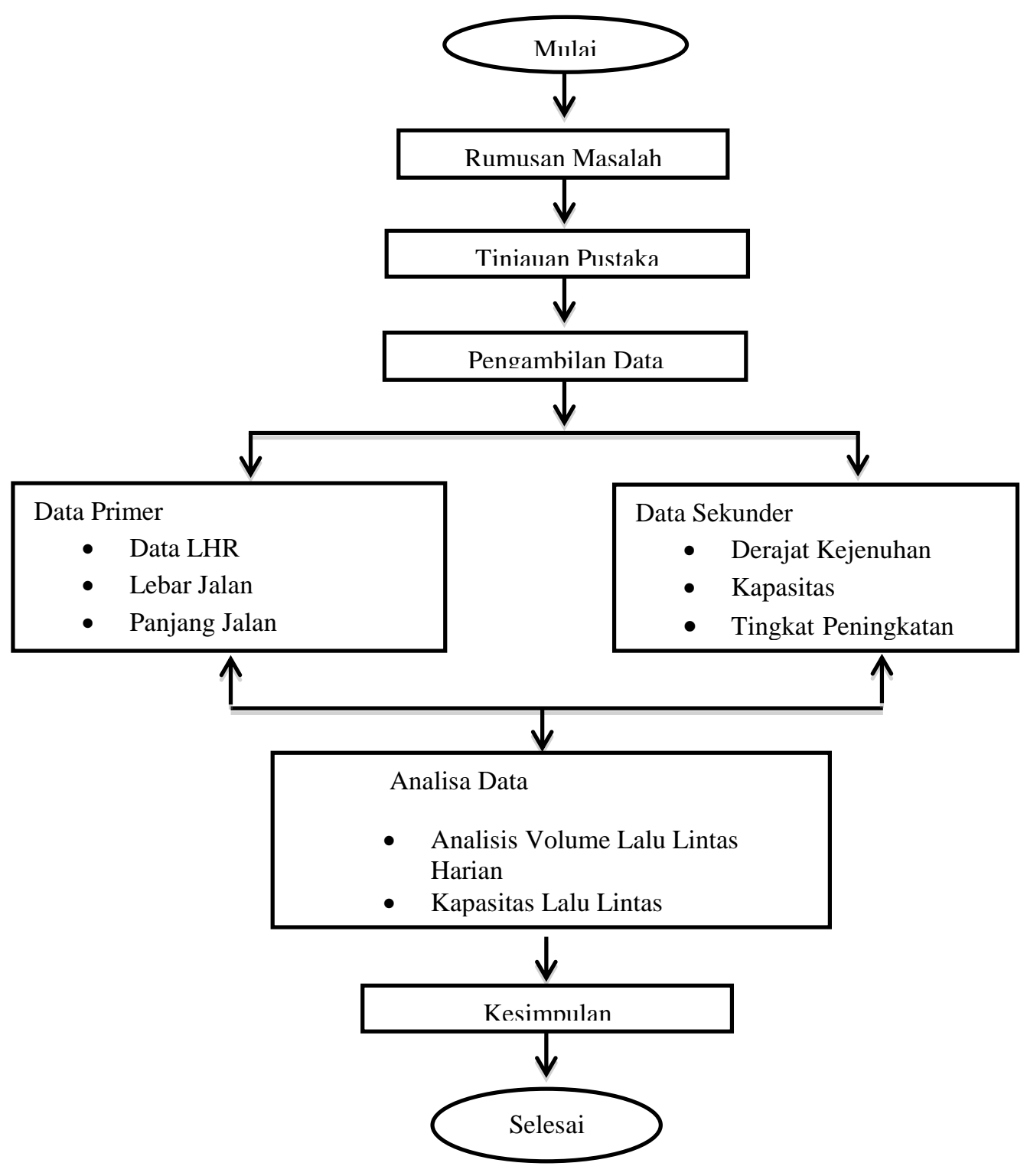

Gambar .2 Bagan Alur Flow chart 
HASIL

Lokasi penelitian berada di Kelurahan Tande Timur Dusun Lutang, dengan tata guna lahan yaitu empang, bangunan sekolah, gedung, dan pemukiman. Waktu pengamatan dilakukan pada pukul 06.00-18.00 WITA.

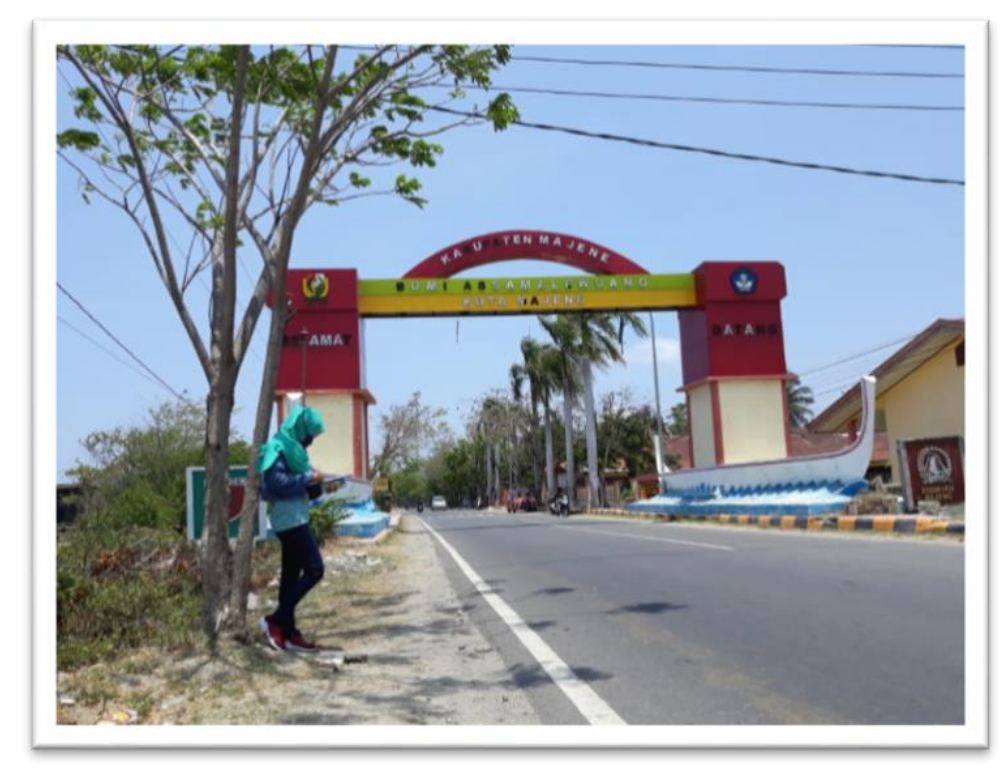

Gambar 3 : Lokasi Penelitian

Hasil pengukuran dilapangan, lebar jalan $9 \mathrm{~m}$ dan lebar bahu jalan satu (1) $\mathrm{m}$ dengan panjang $1 \mathrm{Km}$. Ruas Jalan merupakan jalan arteri atau Jalan Trans Sulawesi yang menghubungkan antara Kabupaten Majene dan Kabupaten Polewali Mandar dapat dilihat dari gambar di atas.

Tabel. 1 Volume kendaraan 2017

\begin{tabular}{|c|l|c|c|}
\hline \multirow{2}{*}{ NO } & \multirow{2}{*}{ JENIS KENDARAAN } & \multicolumn{2}{c|}{ JUMLAH KENDARAAN } \\
\cline { 3 - 4 } & & MASUK & KELUAR \\
\hline 1 & Sepeda Motor & 82.569 & 76.778 \\
\hline 2 & Angkutan Umum & 58.216 & 56.023 \\
\hline 3 & Angkutan Non Umum & 34.156 & 36.181 \\
\hline 4 & Angkutan Barang & 20.506 & 20.595 \\
\hline
\end{tabular}

Sumber : Dinas Perhubungan 2017 
Pada tabel 1 menunjukkan bahwa volume kendaraan dari setiap jenis kendaraan berbeda. Pada kendaraan sepeda motor yang masuk berjumlah 82.569 unit sedangkan jumlah kendaraan sepeda motor yang keluar sebanyak 76.778 unit, kendaraan angkutan non umum yang masuk berjumlah 34.156 unit sedangkan jumlah kendaraan angkutan non umum yang keluar sebanyak 36.181 unit, kendaraan angkutan umum yang masuk berjumlah 58.216 unit sedangkan jumlah kendaraan angkutan umum yang keluar sebanyak 56023 unit, dan untuk kendaraan angkutan barang yang masuk berjumlah 20.506 unit sedangkan jumlah kendaraan angkutan barang yang keluar sebanyak 20.595 unit.

Tabel. 2 Volume kendaraan 2018

\begin{tabular}{|c|l|c|c|}
\hline \multirow{2}{*}{ NO } & \multirow{2}{*}{ JENIS KENDARAAN } & \multicolumn{2}{|c|}{ JUMLAH KENDARAAN (Unit) } \\
\cline { 3 - 4 } & & MASUK & KELUAR \\
\hline 1 & Sepeda Motor & 98.207 & 96.292 \\
\hline 2 & Angkutan Umum & 74.405 & 74.683 \\
\hline 3 & Angkutan Non Umum & 76.263 & 85.663 \\
\hline 4 & Angkutan Barang & 88.801 & 82.857 \\
\hline
\end{tabular}

Sumber : Data jenis dan Jumlah Kendaraan 2018

Pada tabel 2. menunjukkan bahwa volume kendaraan dari setiap jenis kendaraan berbeda. Pada kendaraan sepeda motor yang masuk berjumlah 98.207 unit sedangkan jumlah kendaraan sepeda motor yang keluar sebanyak 96.292 unit, kendaraan angkutan non umum yang masuk berjumlah 76.263 unit sedangkan jumlah kendaraan angkutan non umum yang keluar sebanyak 85.663 unit, kendaraan angkutan umum yang masuk berjumlah 74.405 unit sedangkan jumlah kendaraan angkutan umum yang keluar sebanyak 74.683 unit, dan untuk kendaraan angkutan barang yang masuk berjumlah 88.801 unit sedangkan jumlah kendaraan angkutan barang yang keluar sebanyak 82.857 unit.

\section{PEMBAHASAN}

Hasil analisis volume lalu lintas harian yang diperoleh dilapangan pada tahun 2018 meningkat pada bulan September - Oktober. Hal ini dikarenakan pada akhir bulan Agustus terjadi bencana alam di Provinsi Sulawesi Tengah sehingga hal ini sangat berpengaruh pada peningkatan volume arus lalu lintas di sepanjang jalan lokasi penelitian. Untuk menghitung Volume Jalan Arteri Dusun Lutang, digunakan suatu pendekatan sesuai dengan karakteristik ruas jalannya. Adapun Volume jalan yang di amati pada selama dua bulan diuraikan sebagai berikut:

Dengan :

$$
\mathrm{Q}=\mathrm{N} / \mathrm{T}
$$

$\mathrm{Q}=$ Volume

$\mathrm{N}=$ JumlahKendaran

$\mathrm{T}=$ WaktuPengamatan 


\section{a. Hasil Perhitungan Volume Tahun 2018}

$\mathrm{Q}=677,171$ Unit / $24 \mathrm{Jam}$

$=28,215 \mathrm{Unit} / \mathrm{Jam}$

b. Hasil Perhitungan Volume Bulan September - Oktober Tahun 2018

$$
\begin{array}{cl}
\text { Bulan 9 Q } & =599,594 \text { Unit / } 12 \text { Jam } \\
=4.966 & \text { Unit/Jam } \\
\text { Bulan 10 Q } & =321.289 \text { Unit / } 12 \mathrm{Jam} \\
= & 26.774 \text { Unit/Jam. }
\end{array}
$$

\begin{tabular}{|c|c|c|c|c|c|c|c|c|}
\hline \multirow{2}{*}{ NO } & \multirow{2}{*}{ WAKTU } & \multicolumn{7}{|c|}{ Volume Lalu Lintas Harian (LHR) Kendaraan (Unit) } \\
\hline & & Senin & Selasa & Rabu & Kamis & Jumat & Sabtu & Minggu \\
\hline 1 & 06.00-07.00 & 350 & 330 & 280 & 290 & 300 & 200 & 133 \\
\hline 2 & $07.00-08.00$ & 300 & 289 & 321 & 310 & 295 & 189 & 100 \\
\hline 3 & 08.00-09.00 & 340 & 279 & 350 & 240 & 220 & 167 & 95 \\
\hline 4 & $09.00-10.00$ & 281 & 218 & 281 & 250 & 280 & 160 & 90 \\
\hline 5 & $10.00-11.00$ & 280 & 260 & 280 & 160 & 250 & 150 & 100 \\
\hline 6 & $11.00-12.00$ & 272 & 341 & 300 & 250 & 233 & 180 & 110 \\
\hline 7 & $12.00-13.00$ & 280 & 290 & 310 & 290 & 280 & 150 & 88 \\
\hline 8 & $13.00-14.00$ & 281 & 280 & 211 & 300 & 211 & 167 & 85 \\
\hline 9 & $14.00-15.00$ & 320 & 270 & 241 & 218 & 241 & 175 & 92 \\
\hline 10 & $15.00-16.00$ & 310 & 300 & 222 & 300 & 222 & 200 & 150 \\
\hline 11 & $16.00-17.00$ & 280 & 250 & 280 & 250 & 280 & 220 & 195 \\
\hline 12 & $17.00-18.00$ & 390 & 350 & 300 & 260 & 300 & 300 & 140 \\
\hline
\end{tabular}

Hasil analisis volume lalu lintas harian yang diperoleh dilapangan pada tahun 2018 dapat dilihat pada Tabel 3 berikut ini:

Tabel 3. Volume Lalu Lintas Harian di Jalan Prof. DR. Baharuddin Lopa 2018 


\begin{tabular}{|l|l|l|l|l|l|l|l|}
\hline Jumlah & 3,684 & 3,457 & 3,376 & 3,118 & 3,112 & 2,258 & 1,378 \\
\hline
\end{tabular}

Pada tabel. 3 menunjukkan bahwa volume lalu lintas harian setiap harinya meningkat dan yang paling meningkat pada hari senin jam 17.00 - 18.00 dengan jumlah 390 unit, yang paling rendah terjadi pada jam 11.00 - 12.00 dengan jumlah 272 unit, dan pada hari minggu volume lalu lintas harian paling tinggi pada jam 16.00 - 17.00 dengan jumlah kendaraan 195 unit, yang paling rendah terjadi pada jam 13.00 - 14.00 dengan jumlah kendaraan 85 unit.

\section{PENUTUP}

\section{A. Kesimpulan}

Hasil penelitian menunjukan bahwa Volume Lalu Lintas mengalami peningkatan dari tahun ketahun. Volume Lalu Lintas pada ruas jalan Prof.Dr. Baharuddin Lopa Lutang Majene (Batas Kabupaten Majene - Polewali Mandar) dalam dua (2) tahun terakhir. Tahun 2017 dengan jumlah kendaraan yang masuk dan keluar sebanyak 385.024 Unit atau 3.85\%. Sedangkan Tahun 2018 yang masuk dan keluar sebanyak 677.171 Unit atau 6.77\%. Volume Lalu Lintas Harian (LHR) bulan September dengan jumlah kendaraan sebanyak 59.594 Unit atau 5.95\% dan bulan Oktober sebanyak 321.289 Unit atau 3.21\%. Hal ini dikarenakan pada akhir bulan Agustus terjadi bencana alam di Provinsi Sulawesi Tengah sehingga hal ini sangat berpengaruh pada peningkatan volume arus lalu lintas di sepanjang jalan lokasi penelitian dan sangat berpengaruh dengan hari Kerja.

Volume lalu lintas mendekati atau berada pada kapasitas arus stabil, tingkat pelayanan jalan (LOS) berada pada kategori $\mathrm{C}$ dengan nilai 0,45-0,74 dengan mengacu pada Manual Kapasitas Jalan Indonesia.

\section{A. Saran}

Adapun saran terhadap pembaca dari hasil penelitian ini sebagai berikut:

1. Penelitian ini hanya melakukan survey dua (2) bulan Tahun 2018 sehingga memiliki kekurangan data karena tidak melakukan penelitian sepanjang tahun.

2. Bagi pemerintah perlunya penambahan bahu jalan dan trotoar untuk pejalan kaki guna meningkatkan volume arus lalu lintas.

3. Membuat rambu-rambu jalan untuk meningkatkan volume arus lalu lintas.

4. Bagi masyarakat yang berada pada ruas jalan Prof.Dr Baharuddin Lopa Lutang Majene agar tidak memarkir kendaraan sembarangan.

5. Diharapkan kepada penenliti selanjutnya dapat meneliti hambatan samping, kinerja jalan pada ruas jalan Prof.Dr. Baharuddin Lopa Lutang Majene.

\section{DAFTAR PUSTAKA}

Aly (2013) Performance Analysis Roads and Mobility Vehicle on Urban Road in Independence Pioneer Road.

A Murtopo, (2013) Analysis of Road Traffic Accidents C

ıva Province

Basuki. (2008). Performance of Urban Roads Jalan Prof. dr. Satrio, DKI Jakarta. Civil Tejnik Journal vol 9 no.1. Bandung. Bandung Institute of Technology.

BPS, (2017). Characteristics of Urban Road. 
Department of Transportation, (2017) and Passenger Vehicle Data Exit-Entry in Regency Majene Year (2017).

Directorate General of Highways. 1997 Highway Capacity Manual Indonesia (MKJI). Jakarta. Bina Karya

Miro, (1997). Road classification according to the role, which divides the roads according to function in the road network system.

Muhammad Adam, (2014) Capacity Study Soekarno-Hatta road Greenshild Palembang using during the day and night with the lighting street lamps.

Palin and Rumayar, Lintong, (2013) Capacity and Service Level Jalan Wolter Menginsidi Manado.

Son, (2012) Analysis of Highway Segment Performance Due to Generation Movement Of Sukawati Sukawati Art. Electronic Scientific Journals Infrastructure Civil Engineering Vol 3.

Rahmat, (2007). Performance Analysis and Service Level Pedestrian Facilities Shopping Center in Bandar Lampung. Journal engineering etc. Lampung.Lampung. Etc. Lampung

Setyanto, (2014). Performance of Urban Roads Roads Prof.Dr.Satrio, DKI Jakarta. Journal of Urban and Regional Planning, vol. 20 no. 3. Jakarta. Provincial Government. DKI Jakarta

Sukirman, (2004). Roads and congestions. Bandung. Nova. Journal of Urban and Regional Planning, vol. 20 no. 3. Jakarta. Provincial Government. DKI Jakarta

Tamin, (2014) Geometric An Avenue which consists of several physical elements.

Yunianta, (2006) Road Condition, Condition of Roads and Traffic Conditions. 